\title{
Daily Use of Extra Virgin Olive Oil with High Oleocanthal Concentration Reduced Body Weight, Waist Circumference, Alanine Transaminase, Inflammatory Cytokines and Hepatic Steatosis in Subjects with the Metabolic Syndrome: A 2-Month Intervention Study
}

Angelo M. Patti ${ }^{1,+}$, Giuseppe Carruba ${ }^{2,+} \mathbb{C}$, Arrigo F. G. Cicero ${ }^{3,+}{ }^{\circ}$, Maciej Banach ${ }^{4,5,+}$, Dragana Nikolic ${ }^{1, *, \dagger}$, Rosaria V. Giglio ${ }^{1}$, Antonino Terranova ${ }^{1}$, Maurizio Soresi ${ }^{1}{ }^{1}$, Lydia Giannitrapani ${ }^{1}$, Giuseppe Montalto ${ }^{1}$, Anca Pantea Stoian $\left.{ }^{6}{ }^{(}\right)$, Yajnavalka Banerjee ${ }^{7}{ }^{(D)}$, Ali A. Rizvi ${ }^{8,9}$, Peter P. Toth ${ }^{10,11,12}$ and Manfredi Rizzo ${ }^{1,8}$

1 Department of Health Promotion Sciences Maternal and Infantile Care, Internal Medicine and Medical Specialties (PROMISE), University of Palermo, 90127 Palermo, Italy; pattiangelomaria@gmail.com (A.M.P.); rosaria.vincenza.giglio@alice.it (R.V.G.); toninoterranova@unipa.it (A.T.); maurizio.soresi@unipa.it (M.S.); lydiagiannitp@gmail.com (L.G.); giuseppe.montalto@unipa.it (G.M.); manfredi.rizzo@unipa.it (M.R.)

2 Division of Research and Internationalization, ARNAS-Civico Di Cristina e Benfratelli Hospital, 90127 Palermo, Italy; giuseppe.carruba@arnascivico.it

3 Medical and Surgical Sciences Department, University of Bologna, 40138 Bologna, Italy; arrigo.cicero@unibo.it

4 Department of Hypertension, Chair of Nephrology and Hypertension, Medical University of Lodz, 90-419 Lodz, Poland; Maciej.banach@iczmp.edu.pl

5 Polish Mother's Memorial Hospital Research Institute (PMMHRI) in Lodz, 93-338 Lodz, Poland

6 Department of Diabetes, Nutrition and Metabolic Diseases, Carol Davila University of Medicine and Pharmacy, 050474 Bucharest, Romania; ancastoian@yahoo.com

7 Mohammed Bin Rashid University of Medicine and Health Sciences, 505055 Dubai, UAE; Yajnavalka.Banerjee@mbru.ac.ae

8 Division of Endocrinology, Diabetes and Metabolism, University of South Carolina School of Medicine, Columbia, SC 29203, USA; ali.abbas.rizvi@emory.edu

9 Division of Endocrinology, Metabolism, and Lipids, Emory University School of Medicine, Atlanta, GA 30322, USA

10 CGH Medical Center, Sterling, IL 61081, USA; peter.toth@cghmc.com

11 School of Medicine, University of Illinois, Peoria, IL 60612, USA

12 Johns Hopkins University School of Medicine, Baltimore, MD 21205, USA

* Correspondence: dragana.nikolic@unipa.it; Tel.: +39-09-1655-4703

+ These authors contributed equally to the work.

Received: 31 August 2020; Accepted: 30 September 2020; Published: 2 October 2020

\begin{abstract}
Extra virgin olive oil (EVOO) intake is associated with reduced cardiovascular risk, and its phenolic compound oleocanthal (OC) has anti-oxidant and anti-inflammatory properties. The cardiometabolic effects of EVOO with a high OC concentration have not been fully elucidated. We administered EVOO with a high OC concentration daily to 23 subjects with the metabolic syndrome (MetS) and hepatic steatosis (15 men and 8 women, age: $60 \pm 11$ years) for 2 months. Anthropometric data, metabolic parameters, hepatic steatosis (by fatty liver index, FLI), abdominal fat distribution (by ultrasound), and pro- and anti-inflammatory cytokines were assessed before and after the intervention. EVOO supplementation was associated with a reduction in body weight, waist circumference, body mass index (BMI), alanine transaminase and FLI, as well as interleukin (IL)-6, IL-17A, tumor necrosis factor- $\alpha$ and IL-1B, while IL-10 increased. Maximum subcutaneous
\end{abstract}


fat thickness (SFT max) also increased, with a concomitant decrease in the ratio of visceral fat layer thickness/SFT max. Correlation analysis revealed positive associations between changes in body weight and BMI and those in SFT max, along with an inverse association between changes in IL-6 and those in SFT max. In conclusion, ingestion of EVOO with a high OC concentration had beneficial effects on metabolic parameters, inflammatory cytokines and abdominal fat distribution in MetS subjects with hepatic steatosis, a category of patients at high cardiometabolic risk.

Keywords: metabolic syndrome; olive oil; oleocanthal; polyphenols; cytokines

\section{Introduction}

The relationship between the traditional Mediterranean diet (MD) and human health has been known since ancient times and several studies have shown the beneficial effects of the MD in preventing diabetes and cardiovascular diseases (CVD) [1-3], as well as those on weight control, without significant adverse events [4-6]. Extra virgin olive oil (EVOO) is a major component in the MD [7], being recognized as one of the healthiest products originating from the Mediterranean region [7]. The beneficial properties belonging to EVOO have been ascribed to its components, especially to the phenolic constituents [8-11]. Oleocanthal (OC) is a phenolic compound found mostly in EVOO which is responsible for its bitter taste, having strong anti-inflammatory properties based on the inhibition of cyclooxygenase (COX) [12]. For this reason, OC is recognized as a natural non-steroidal anti-inflammatory agent [13-16].

Several studies have shown that the phenolic compounds of EVOO have beneficial anti-inflammatory, anti-microbial and anti-oxidant activities [17]. It has been also suggested that long-term daily intake of OC-containing EVOO may be, at least in part, responsible for the health protection of Mediterranean populations [12]. Yet, the metabolic syndrome (MetS) is rapidly increasing in such populations, since dietary habits and lifestyles have strongly changed in the last decades [18,19]. A growing number of studies indicate that nutraceuticals have several benefits on more than one component of the MetS [20-25]. In addition, nonalcoholic fatty liver disease is one of the emerging components of the MetS [26-28]. The presence of hepatic steatosis in MetS subjects is a negative prognostic factor for future cardiometabolic events and is associated with future events independently of other cardiovascular (CV) risk factors [29]. Increasing evidence suggests that nutraceuticals can have several benefits on hepatic parameters in MetS subjects [30], but the effects of EVOO and OC on MetS, with or without the presence of hepatic steatosis, are still unknown.

The aim of this study was to evaluate the effects of daily use of EVOO rich in OC, on anthropometric, metabolic and inflammatory parameters, as well as on abdominal fat distribution, in subjects with the MetS and hepatic steatosis, which represents a category of patients at high risk for developing future cardiometabolic events.

\section{Results}

We found that 2 months of EVOO supplementation led to a significant reduction in body weight, body mass index (BMI), waist circumference, alanine transaminases (ALT) and fatty liver index (FLI) in MetS patients with hepatic steatosis (Table 1).

In addition, we tested if there were any gender-specific changes in the cardiometabolic effects of EVOO after the supplementation, although the number of women was low. In men, only waist circumference, and in women, only body weight significantly changed after 2 months (data not shown). However, when comparing the two groups, the differences between genders did not reach statistical significance for any parameter. 
Table 1. Effect of extra virgin olive oil (EVOO) with a high oleocanthal (OC) concentration on anthropometric and laboratory parameters $(n=23)$.

\begin{tabular}{cccc}
\hline & Baseline & After 2 Months & $p$-Value \\
\hline Body weight $(\mathrm{kg})$ & $87 \pm 17$ & $85 \pm 16$ & 0.035 \\
BMI $\left(\mathrm{kg} / \mathrm{m}^{2}\right)$ & $31 \pm 4$ & $30 \pm 4$ & 0.031 \\
Waist circumference (cm) & $108 \pm 12$ & $105 \pm 10$ & 0.037 \\
Glycemia (mmol/L) & $5.35 \pm 1.11$ & $5.86 \pm 1.34$ & 0.055 \\
HbA1c $(\%)$ & $6.13 \pm 0.60$ & $6.05 \pm 0.45$ & 0.192 \\
Total cholesterol (mmol/L) & $4.61 \pm 0.98$ & $4.60 \pm 0.89$ & 0.851 \\
HDL-cholesterol (mmol/L) & $1.17 \pm 0.25$ & $1.16 \pm 0.25$ & 0.392 \\
LDL-cholesterol (mmol/L) & $2.82 \pm 0.72$ & $2.72 \pm 0.69$ & 0.422 \\
Triglycerides (mmol/L) & $1.74 \pm 0.75$ & $1.71 \pm 0.98$ & 0.909 \\
Aspartate transaminases (AST) (mU/mL) & $29.21 \pm 26.88$ & $22.32 \pm 7.52$ & 0.167 \\
Alanine transaminases (ALT) (mU/mL) & $38.52 \pm 30.56$ & $29.64 \pm 20.62$ & 0.029 \\
Gamma glutamyl transferase (GGT) (U/L) & $32.30 \pm 17.24$ & $30.50 \pm 17.41$ & 0.284 \\
Non-HDL-cholesterol & $3.44 \pm 0.73$ & $3.44 \pm 0.64$ & 0.987 \\
Fatty liver index & $74.80 \pm 18.57$ & $69.01 \pm 22.06$ & 0.004 \\
\hline
\end{tabular}

BMI: body mass index; EVOO: extra virgin olive oil; HbA1c: glycated hemoglobin; HDL: high density lipoprotein; LDL: low density lipoprotein; OC: oleocanthal.

In addition, levels of all the measured pro-inflammatory cytokines (IL (interleukin)-6, IL-17A, TNF- $\alpha$, IL-1B) decreased significantly, while concentrations of the anti-inflammatory cytokine IL-10 significantly increased (Table 2).

Table 2. Effect of EVOO with a high OC concentration on plasma cytokines.

\begin{tabular}{cccc}
\hline & Baseline & After 2 Months & $p$-Value \\
\hline IL-6 $(\mathrm{pg} / \mathrm{mL})$ & $2.9 \pm 2.2$ & $2.0 \pm 1.9$ & 0.020 \\
IL-17A $(\mathrm{pg} / \mathrm{mL})$ & $3.2 \pm 4.0$ & $1.5 \pm 1.3$ & 0.044 \\
TNF- $\alpha(\mathrm{pg} / \mathrm{mL})$ & $7.3 \pm 2.2$ & $6.3 \pm 2.1$ & 0.003 \\
IL-1B $(\mathrm{pg} / \mathrm{mL})$ & $0.8 \pm 1.4$ & $0.2 \pm 0.3$ & 0.045 \\
IL-10 $(\mathrm{pg} / \mathrm{mL})$ & $0.4 \pm 0.4$ & $0.9 \pm 1.3$ & 0.039 \\
\hline
\end{tabular}

Regarding abdominal fat distribution, we found that the maximum subcutaneous fat thickness (SFT max) significantly increased after olive oil supplementation, with a concomitant reduction in the ratio of visceral fat layer thickness/max. subcutaneous fat thickness (Table 3).

Table 3. Effect of EVOO with a high OC concentration on abdominal ultrasound parameters.

\begin{tabular}{cccc}
\hline & Baseline & After 2 Months & $p$-Value \\
\hline Visceral fat layer thickness (mm) & $6.42 \pm 2.23$ & $6.32 \pm 2.15$ & 0.815 \\
Min. subcutaneous fat thickness (mm) & $1.18 \pm 0.61$ & $1.34 \pm 0.51$ & 0.170 \\
Max. subcutaneous fat thickness (mm) & $1.67 \pm 0.74$ & $2.19 \pm 0.78$ & 0.003 \\
Min. pre-peritoneal fat thickness (mm) & $0.56 \pm 0.36$ & $0.55 \pm 0.23$ & 0.633 \\
Max. pre-peritoneal fat thickness (mm) & $1.22 \pm 0.82$ & $1.11 \pm 0.45$ & 0.679 \\
Ratio visceral fat layer thickness/max. & $3.98 \pm 1.63$ & $3.28 \pm 1.49$ & 0.020 \\
$\quad$ subcutaneous fat thickness & & & \\
\hline
\end{tabular}

EVOO: extra virgin olive oil; OC: oleocanthal.

We also performed correlation analysis in order to assess potential associations between changes in all evaluated parameters (data not shown). There was a significant association between changes in both body weight and BMI and those in SFT $\max (r=0.426, p=0.043 ; r=0.490, p=0.018$, respectively) and between changes in both body weight and BMI and those in the minimum pre-peritoneal fat thickness (PFT min) $(r=0.561, p=0.012 ; r=0.525, p=0.021$, respectively). In addition, we found 
a significant association between changes in IL-6 and those in SFT max $(r=-0.505, p=0.014)$ and between changes in IL-1B and those in PFT max $(r=0.662, p=0.026)$.

\section{Discussion}

It is well known that the MD represents a dietary pattern characterized by the presence of different varieties of whole cereals, fresh fruits and vegetables, wheat products (bread, pasta), legumes, potatoes, beans, nuts and seeds, milk products (such as cheese and yogurt), blue fish and poultry consumed in moderate quantities, and a low consumption of red meat, refined sugar and animal fat. However, one of the main distinctive components of the MD is EVOO, representing the main source of dietary fat and polyphenols [31,32], the latter being potent inhibitors of reactive oxygen species and associated with a reduced risk for CVD and several types of cancer [2,33-36]. Several studies confirmed the beneficial effects of polyphenols in olive oil on heart disease risk factors and oxidative damage [37-40]. In addition, EVOO has been widely studied for its favorable effects on plasma concentrations of low-density lipoprotein cholesterol (LDL-C) and total cholesterol [33,39,41-43], as well as on blood pressure [43-45].

Owen et al. [46] suggested that the antioxidant phenolic fraction, along with high contents of squalene and oleic acid, may confer to olive oil its health-promoting properties. In this context, the Epicor study, investigating the association between consumption of fruits, vegetables, and olive oil and the incidence of coronary heart disease (CHD), has shown that the consumption of olive oil in the diet leads to a reduction in CVD risk in middle-aged Italian women without a diagnosis of stroke, myocardial infarction, diabetes or hyperlipidemia [47]. EVOO is able to counteract postprandial oxidative stress through down-regulation of nicotinamide adenine dinucleotide phosphate oxidase (NOX2) [48] and reduces the risk of diabetes among people at a high CVD risk [20,49,50]. The Primary Prevention of Cardiovascular Disease with Mediterranean Diet (PREDIMED) study, with a total of 7447 persons enrolled [51], has also shown that the addition of EVOO to an MD reduces the risk the incidence of major CV events.

There are several studies that have considered the effects of other polyphenols derived from EVOO, but none have evaluated the clinical effects of EVOO with a high concentration of its phenolic compound OC. Previous studies have reported OC activity as a potent antioxidant and as a non-steroidal anti-inflammatory agent [12]. In fact, Beauchamp et al. [12] showed that the structure of OC and that of the anti-inflammatory drug ibuprofen share a similar molecular geometry and, like ibuprofen, OC exhibits COX-inhibiting activity. Furthermore, consumption of $9 \mathrm{mg}$ of OC per day mediates an anti-inflammatory effect, which is equivalent to that achieved by $90 \mathrm{mg}$ of ibuprofen. MetS is a constellation of disturbances detrimentally affecting the metabolic homeostasis of an individual, where metabolic overload induces stress reactions, such as oxidative, inflammatory, organelle and cell hypertrophy, leading to a vicious cycle where environmental, genetic and psychosocial factors interact through complex networks [52]. The difficulty in the management of MetS is a consequence of its multifactorial nature, where environmental, genetic and psychosocial factors interact through intricate networks, although inflammation is one of the key underlying factors spurring the progression of MetS and is directly linked to the adverse CV outcome [53,54]. Therefore, it is essential to assess novel anti-inflammatory strategies, especially in subjects with the MetS, for comprehensive cardiometabolic prevention [55-57].

In the present study, we have assessed the impact of EVOO with a high percentage of OC on metabolic parameters and abdominal fat distribution, as well as on pro- and anti-inflammatory cytokines, in adults with the MetS and hepatic steatosis, a population known to be at high risk for atherosclerotic CVD [58]. To the best of our knowledge, the present study is the first one to determine the beneficial effects of EVOO with a high percentage of OC in such high-risk subjects. We found that the consumption of high-OC EVOO beneficially affected the anthropometric parameters evaluated, with a reduction in body weight, BMI and waist circumference. Furthermore, although subjects did not change their lifestyle or eating habits, 2 months of dietary intervention with olive oil were enough 
to significantly reduce those parameters. The observed effects may be due to increased postprandial fat oxidation, which has been observed after a meal rich in olive oil [59]. On the other hand, a recent study showed that an MD enriched with EVOO can be an effective alternative option to low-fat diets for weight maintenance regimes in older overweight or obese adults [60].

We did not find, in the present study, any statistically significant variation in plasma lipids and glycemic parameters, such as fasting glycemia and glycated hemoglobin (HbA1c). Similarly, in a randomized placebo-controlled trial including 41 overweight and obese adults, the substitution of commonly used oil with EVOO for 3 months did change glycaemia and plasma lipids [61]. However, the absence of significant changes in these parameters may also be due to the relative short duration time and sample size of the study. Indeed, in a crossover study including 200 healthy male volunteers who were randomly assigned to three sequences of daily administration of $25 \mathrm{~mL}$ of three different olive oils (with a low, medium or high phenolic content), benefits on plasma lipids have been found [62]. Of interest, in the present study, we observed that the supplementation of EVOO with a high OC concentration significantly reduced ALT in MetS patients with hepatic steatosis, and it is known that transaminase concentrations are associated with the degree of hepatic steatosis, as assessed by ultrasound [63]. Therefore, although not directly demonstrated, we cannot exclude that olive oil use led to an improved degree of hepatic steatosis, which is supported by improved FLI, in spite of the limited period of follow-up. Furthermore, the hepato-protective action of EVOO, has been demonstrated in animals [64] and later confirmed in humans [65,66], although the effect of OC on hepatic function is still unclear.

Regarding abdominal fat distribution, we found a significant increase in SFT max, with a decrease in the ratio of visceral fat layer thickness/SFT max. This finding may have important clinical implications since visceral adipose tissue (VAT) is considered to be more metabolically active than subcutaneous adipose tissue (SAT), having a different capacity to secrete adipokines/cytokines, hormones and immune molecules [67]. It is also well documented that an excess of VAT can be considered as a good marker of an altered cardiometabolic risk profile associated with increased CVD risk [68]. Correlation analysis revealed positive associations between changes in body weight and BMI and those in SFT max, highlighting the concomitant effects of the supplementation of EVOO with a high OC concentration on anthropometric parameters and abdominal fat distribution.

It has been previously reported that in healthy subjects, serum lipid levels were associated with total body fat, but more specifically abdominal SAT, with an association between serum triglycerides and waist circumference; in addition, in that population, levels of inflammatory IL-18 cytokine were associated with small, dense LDL $[69,70]$. Indeed, the quality, rather than only the quantity, of LDL-C is strongly associated with CV risk, with atherogenic small, dense LDL being a novel marker of such risk [71,72]. The relationship between inflammation, oxidative stress and small, dense LDL is very strict [73], with the latter representing a main feature of the MetS [74], and, even more, a strong predictive marker for future CV and cerebrovascular events in MetS patients [75]. It would be, therefore, of clinical value to assess, in future studies, the effect of EVOO with a high content in OC on small, dense LDL as well as on HDL functionality, beyond plasma lipid levels [76].

In the present study we also found that levels of pro-inflammatory cytokines (IL-6, IL-17A, TNF- $\alpha$ and IL-1B) significantly decreased, while those of anti-inflammatory cytokine (IL-10) significantly increased. This data suggests that the consumption of EVOO with a high content of OC can have important anti-inflammatory effects, and it is consistent with the natural anti-inflammatory properties of OC $[14,77,78]$. It has been previously reported that one of the mechanisms underlying the anti-inflammatory properties of OC is the inhibition of the nuclear factor- $k B(N F-k B)$ pathway [79], which in turn may not only reduce the levels of pro-inflammatory cytokines but also attenuate cortical cyclooxygenase-2 (COX-2) signaling [80]. However, further investigations are needed for a better understanding of this aspect. Interestingly, a preclinical study has shown that an EVOO-enriched diet had the best results on the musculoskeletal system in an osteoarthritis rat model, including decreased IL-6 expression [65]. On the other hand, an MD rich in high quality EVOO also significantly increases 
IL-10 levels [40]. By correlation analysis, we interestingly found an inverse association between changes in IL-6 and those in SFT max, which further highlights the concurrent effects of olive oil supplementation on anti-inflammatory cytokines and abdominal fat distribution.

Potential limitations of the present study include the small number of subjects included; however, this allowed us to monitor the study population closely ensuring the participants adhered to the desired regimen, even more since it was a different type of pasta to be consumed almost daily. Furthermore, our study was open-label and lacked a control (placebo) group; however, all patients, prior to the intake of EVOO with high OC, followed an MD with EVOO containing standard contents of OC; therefore, this somewhat overcame the need of a placebo control group, since the population included in the study acted as their own control. Lastly, our study had a relatively short intervention period with only two points of measurements (baseline and end of the follow-up period), which made us unable to look at the variables in the continuous way, a fact that should be addressed in future studies.

Nevertheless, this study has several strengths, including the mono-cultivar type of olive oil and the novelty of the study with regards to the design strategy, as well as the large number of biochemical and ultrasound parameters assessed. All measurements were assessed in a blinded manner, which means that the ultrasound operator did not have access to previous scans, and all the biochemical parameters were assessed in aliquots with blinded codes.

\section{Materials and Methods}

\subsection{Study Design}

Mono-cultivar EVOO with a high OC content was supplied by Prof. Tiziano Caruso from the Department of Agriculture and Forestry Sciences, University of Palermo, Italy, and used for the purpose of this study only. All patients were referred to our Unit of Diabetes and Cardiovascular Prevention for a clinical evaluation and included in the study consequently. The olive oil was administered to 23 subjects with the MetS at a fixed dose of 4 large spoons daily (which corresponded to $32 \mathrm{~g}$ of EVOO) during their main meals, e.g., at lunch and dinner, for a period of 60 days. The study population prior to the intake of EVOO with high OC acted as their own control since they followed an MD with EVOO containing standard contents of OC. This is one of the strengths of the study, as it allowed us to monitor the different parameters for each patient closely, without the specific need of a separate control group. During the study, the dose of the EVOO was maintained unmodified, and no other type of oil was allowed.

Inclusion criteria included: European descent following an MD, age between 18 and 70 years, the diagnosis of MetS as defined by international consensus [81] and the presence of hepatic steatosis (as assessed by abdominal ultrasound). Exclusion criteria included acute and chronic renal failure, liver diseases, acute illnesses, chronic inflammatory or infective diseases and tumors, as well as alcohol consumption (>30 g/day for men and $>20 \mathrm{~g} /$ day for women). All subjects were followed up for 60 days, and a similar evaluation was performed at baseline and after the follow-up period, including a medical examination, biochemical analyses and an abdominal ultrasound. All concomitant therapies were kept constant during the study, and this was achieved in all patients due to the relatively short duration of the study. Notably, all patients did not use any natural supplement for dyslipidemia. The adopted procedures were in agreement with the Helsinki Declaration of 1975 as revised in 1983, and the study was approved by the Ethical Committee of the University of Palermo.

All patients gave informed written consent to participate in the study and completed the "Epic" Food Frequency Questionnaire [82] in order to assess their eating habits and the frequency of consumption of foods and beverages. All patients were accustomed to Mediterranean dietary habits, since they were born and have been living all their life in the same metropolitan area in Italy. During the study, patients were strongly advised not to alter their dietary habits, nor change their lifestyle. In fact, this was ensured carefully by weekly follow-up telephone calls. In line, we followed a similar strategy [83] to ensure that the study population adhered to the desired regimen. Baseline 
characteristics of patients are shown in Table 4. A sedentary lifestyle with little physical activity was common among the subjects.

Table 4. Baseline characteristics of all patients.

\begin{tabular}{|c|c|c|c|c|}
\hline & All Cohort $(n=23)$ & Men $(n=15)$ & Women $(n=8)$ & $p$ Value \\
\hline Age (years) & $60 \pm 11$ & $60 \pm 13$ & $59 \pm 7$ & \\
\hline Women, $n(\%)$ & $8(35)$ & 0 & 8 & $<0.001$ \\
\hline Smoking habit, $n(\%)$ & $4(17)$ & $2(13)$ & $2(25)$ & 0.482 \\
\hline $\begin{array}{c}\text { Family history of } \\
\text { cardiovascular diseases, } n(\%)\end{array}$ & $15(65)$ & $10(67)$ & $5(62)$ & 0.842 \\
\hline $\begin{array}{l}\text { Past history of } \\
\text { cerebro-cardiovascular } \\
\text { diseases, } n(\%)\end{array}$ & $0(0)$ & 0 & 0 & \\
\hline Hypertension, $n(\%)$ & $14(61)$ & $9(60)$ & $5(62)$ & 0.907 \\
\hline Type- 2 diabetes, $n(\%)$ & $12(52)$ & $9(60)$ & $3(37)$ & 0.304 \\
\hline Dyslipidemia, $n(\%)$ & $15(65)$ & $11(73)$ & $4(50)$ & 0.645 \\
\hline Obesity, $n(\%)$ & $14(61)$ & $8(53)$ & $6(75)$ & 0.311 \\
\hline \multicolumn{5}{|l|}{$\begin{array}{c}\text { Use of anti-hypertensive } \\
\text { therapies }\end{array}$} \\
\hline Aeta-blockers, $n(\%)$ & $6(26)$ & $3(20)$ & $3(37)$ & 0.363 \\
\hline $\begin{array}{l}\text { Angiotensin-converting } \\
\text { enzyme inhibitors, } n(\%)\end{array}$ & $10(43)$ & $9(60)$ & $1(12)$ & 0.029 \\
\hline Calcium entry-blockers, $n(\%)$ & $2(9)$ & $1(7)$ & $1(12)$ & 0.636 \\
\hline Diuretics, $n(\%)$ & $4(17)$ & $4(27)$ & 0 & 0.108 \\
\hline \multicolumn{5}{|l|}{ Use of lipid-lowering drugs } \\
\hline Statins, $n(\%)$ & $8(35)$ & $6(40)$ & $2(25)$ & 0.472 \\
\hline Omega-3 fatty acids, $n(\%)$ & $4(17)$ & $2(13)$ & $2(25)$ & 0.482 \\
\hline Ezetimibe, $n(\%)$ & $2(9)$ & $2(13)$ & 0 & 0.280 \\
\hline Aspirin use, $n(\%)$ & $9(39)$ & $8(53)$ & $1(12)$ & 0.056 \\
\hline \multicolumn{5}{|l|}{ Use of hypoglicemic drugs } \\
\hline Biguanides, $n(\%)$ & $10(43)$ & $8(53)$ & $2(25)$ & 0.192 \\
\hline Sulfonylureas, $n(\%)$ & $2(9)$ & $2(13)$ & 0 & 0.280 \\
\hline Liraglutide, $n(\%)$ & $1(4)$ & $1(7)$ & 0 & 0.455 \\
\hline
\end{tabular}

\subsection{Biochemical Analyses}

All blood samples were taken after at least $10 \mathrm{~h}$ overnight fast. We measured by routine laboratory methods plasma lipids as well as serum aspartate transaminases (AST), ALT and gamma glutamyl-transferase (GGT). LDL-C was calculated using the Friedewald formula. FLI score was used as a marker of liver steatosis, with the following formula [84]: FLI $=(\mathrm{e} 0.953 \times \operatorname{loge}(\mathrm{TG})+0.139 \times \mathrm{BMI}$ $+0.718 \times$ loge $(\mathrm{GGT})+0.053 \times$ waist circumference -15.745$) /(1+\mathrm{e} 0.953 \times$ loge $(\mathrm{TG})+0.139 \times \mathrm{BMI}+$ $0.718 \times$ loge $($ GGT $)+0.053 \times$ waist circumference -15.745$) \times 100$.

\subsection{Cytokines' Analyses}

Blood samples were collected in tubes without ethylenediamine tetraacetic acid (EDTA), and serum was separated from whole blood by low-speed centrifugation at $2500 \mathrm{rpm}$ for $15 \mathrm{~min}$ at $4{ }^{\circ} \mathrm{C}$. We analyzed four pro-inflammatory cytokines (IL-6, IL-17A, TNF- $\alpha$, IL-1B) [85-88] and one anti-inflammatory cytokine (IL-10) [89] by Luminex assays, coupled to BioPlex Manager software [90].

\subsection{Ultrasound Examination}

Abdominal fat distribution was assessed by ultrasound in the morning, after fasting for at least $10 \mathrm{~h}$, by a single investigator/physician (AT), in order to avoid the risk of measure-to-measure inter-investigator bias. A real-time Philips $5000 \mathrm{HDI}$ apparatus with a 2-5 MHz convex multi-frequency probe and 5-12 MHz multi-frequency linear probe was used. All patients had hepatic steatosis, 
as an inclusion criteria for the study [91]. Steatosis severity was scored as: grade 1 (mild steatosis), characterized by increased echogenicity; grade 2 (moderate steatosis), accompanied by increased echogenicity and posterior beam attenuation with slightly impaired visualization of the intrahepatic vessels and diaphragm; grade 3 (severe steatosis), with a marked increase in echogenicity and marked posterior beam attenuation resulting in failure to demonstrate the intrahepatic vessels, diaphragm, and posterior right lobe of the liver [92]. All patients included in the present study had moderate steatosis. The SFT max was measured at $5 \mathrm{~cm}$ from the umbilicus on the xypho-umbilical line, whereas the minimum subcutaneous fat thickness was measured from the region just below the xyphoid process [93]. Such measurements were taken directly from the screen using the electronic calipers at the skin-fat (excluding skin) and fat-muscle interfaces, and then the mean thickness was calculated. Preperitoneal fat layer measurements were taken from the region where it is most clearly seen just below the xyphoid process, between the internal face of linea alba and surface of the liver. Measurement of preperitoneal fat at the upper and lower edges of the liver was avoided because the preperitoneal fat layer changes abruptly at these regions. A convex-array probe $(3.5 \mathrm{MHz})$ was used for measuring the visceral fat layer thickness taken between the internal face of the abdominal muscle and the anterior wall of the aorta [94]. All patients were asked to hold their breath during the examination; special care was taken to keep the probe just touching the skin to prevent compression of the fat layers.

\section{Statistical Analysis}

Statistical analyses were performed using SPSS software (V.17.0 for Windows, SPSS Inc., Chicago, IL, USA). All variables were tested for normality using the Kolmogorov-Smirnov test. Data are expressed as mean \pm standard deviation for parametric variables, whereas categorical variables are expressed as percentages. Baseline characteristics were compared using the Chi-square test. We used the paired t-test for normally distributed parameters and Wilcoxon rank test for nonparametric variables, while the Spearman rank correlation method was used for the correlation analysis.

\section{Conclusions}

To our knowledge, this is the first study investigating the effects of EVOO supplementation with a high concentration of OC in subjects with MetS and hepatic steatosis, a category of patients at high risk for developing future cardiometabolic events. Our findings suggest that such olive oil supplementation has multiple beneficial effects on anthropometric and biochemical parameters, including inflammatory cytokines and FLI as well as abdominal fat distribution. Further studies may provide a better understanding of mechanisms underlying the effects of OC on inflammation and, consequently, potential therapeutic approaches for the prevention and/or reduction in overall cardio-metabolic risk in such a high-risk population of MetS patients.

Author Contributions: Design of the study: M.R., D.N., G.C. and A.A.R.; methodology: M.R., A.M.P., D.N., R.V.G. and A.T.; validation: G.C., A.F.G.C., M.B., A.P.S., Y.B., A.A.R. and P.P.T.; statistical analysis: D.N. and R.V.G.; laboratory investigation: D.N. and R.V.G.; clinical investigation: M.R., A.M.P., A.T., M.S., L.G. and G.M.; data curation: D.N., A.M.P., A.T. and M.S.; writing—original draft preparation: M.R., G.C., A.M.P., D.N., A.F.G.C., and M.B.; writing-critical review and editing: R.V.G., A.P.S., Y.B., A.A.R. and P.P.T. All authors have read and agreed to the published version of the manuscript.

Funding: This research received no external funding and has been performed independently, using university research funds only. The authors did not receive financial or professional help with the preparation of the manuscript.

Acknowledgments: The authors want to thank Amedeo Bonfiglio, Giuseppa Castellino and Roberta Chianetta from PROMISE Department, University of Palermo, Italy, for their valuable contribution in a few steps of this study, as well as all the volunteers who participated in this trial. We are grateful to Nicola Locorotondo and Valentina Mistretta for their valuable contribution in the laboratory work. Part of this work was carried out using instruments provided by project DiMeSa (Dieta Mediterranea e Salute) "Valorisation of typical products of Mediterranean Diet and their use for health and nutraceutic aims", PON02_00451_3361785. This project is funded in the frame of National Operative Programme (PON) Research and Competitiveness 2007-2013, Notice 713/Ric. the Ministry of Education, University and Research (MIUR), Axis I-Support to structural changes, Operational 
Objective-Networks to strengthen the scientific and technological potential of Convergence Regions, The Action: High Technology Clusters and Related Networks.

Conflicts of Interest: The authors have given talks, attended conferences and participated in advisory boards and clinical trials sponsored by various pharmaceutical companies. Anca Pantea Stoian is currently Vice President of Romanian National Diabetes Committee. Manfredi Rizzo is currently Chief Medical and Scientific Advisor, Diabetes, Novo Nordisk South East Europe, Middle East and Africa (SEEMEA). The authors declare no conflict of interest, financial or otherwise.

\section{References}

1. Rosato, V.; Temple, N.J.; La Vecchia, C.; Castellan, G.; Tavani, A.; Guercio, V. Mediterranean diet and cardiovascular disease: A systematic review and meta-analysis of observational studies. Eur. J. Nutr. 2019, 58, 173-191. [CrossRef]

2. Cicero, A.F.G.; Colletti, A.; Bajraktari, G.; Descamps, O.; Djuric, D.M.; Ezhov, M.; Fras, Z.; Katsiki, N.; Langlois, M.; Latkovskis, G.; et al. Lipid lowering nutraceuticals in clinical practice: Position paper from an International Lipid Expert Panel. Arch. Med. Sci. 2017, 13, 965-1005. [CrossRef]

3. Sahebkar, A.; Serban, M.C.; Gluba-Brzozka, A.; Mikhailidis, D.P.; Cicero, A.F.; Rysz, J.; Banach, M. Lipid-modifying effects of nutraceuticals: An evidence-based approach. Nutrition 2016, 32, 1179-1192. [CrossRef]

4. Pan, B.; Wu, Y.; Yang, Q.; Ge, L.; Gao, C.; Xun, Y.; Tian, J.; Ding, G. The impact of major dietary patterns on glycemic control, cardiovascular risk factors, and weight loss in patients with type 2 diabetes: A network meta-analysis. J. Evid. Based Med. 2019, 12, 29-39. [CrossRef]

5. Mancini, J.G.; Filion, K.B.; Atallah, R.; Eisenberg, M.J. Systematic Review of the Mediterranean Diet for Long-Term Weight Loss. Am. J. Med. 2016, 129, 407-415.e4. [CrossRef]

6. Esposito, K.; Kastorini, C.M.; Panagiotakos, D.B.; Giugliano, D. Mediterranean diet and weight loss: Meta-analysis of randomized controlled trials. Metab. Syndr. Relat. Disord. 2011, 9, 1-12. [CrossRef]

7. Jimenez-Lopez, C.; Carpena, M.; Lourenco-Lopes, C.; Gallardo-Gomez, M.; Lorenzo, J.M.; Barba, F.J.; Prieto, M.A.; Simal-Gandara, J. Bioactive Compounds and Quality of Extra Virgin Olive Oil. Foods 2020, 9, 1014. [CrossRef]

8. Lozano-Castellon, J.; Lopez-Yerena, A.; Rinaldi de Alvarenga, J.F.; Romero Del Castillo-Alba, J.; Vallverdu-Queralt, A.; Escribano-Ferrer, E.; Lamuela-Raventos, R.M. Health-promoting properties of oleocanthal and oleacein: Two secoiridoids from extra-virgin olive oil. Crit. Rev. Food Sci. Nutr. 2020, 60, 2532-2548. [CrossRef]

9. Yubero-Serrano, E.M.; Lopez-Moreno, J.; Gomez-Delgado, F.; Lopez-Miranda, J. Extra virgin olive oil: More than a healthy fat. Eur. J. Clin. Nutr. 2019, 72, 8-17. [CrossRef]

10. Francisco, V.; Ruiz-Fernandez, C.; Lahera, V.; Lago, F.; Pino, J.; Skaltsounis, L.; Gonzalez-Gay, M.A.; Mobasheri, A.; Gomez, R.; Scotece, M.; et al. Natural Molecules for Healthy Lifestyles: Oleocanthal from Extra Virgin Olive Oil. J. Agric. Food Chem. 2019, 67, 3845-3853. [CrossRef]

11. Lozano-Sanchez, J.; Giambanelli, E.; Quirantes-Pine, R.; Cerretani, L.; Bendini, A.; Segura-Carretero, A.; Fernandez-Gutierrez, A. Wastes generated during the storage of extra virgin olive oil as a natural source of phenolic compounds. J. Agric. Food Chem. 2011, 59, 11491-11500. [CrossRef]

12. Beauchamp, G.K.; Keast, R.S.; Morel, D.; Lin, J.; Pika, J.; Han, Q.; Lee, C.H.; Smith, A.B.; Breslin, P.A. Phytochemistry: Ibuprofen-like activity in extra-virgin olive oil. Nature 2005, 437, 45-46. [CrossRef]

13. Monti, M.C.; Margarucci, L.; Tosco, A.; Riccio, R.; Casapullo, A. New insights on the interaction mechanism between tau protein and oleocanthal, an extra-virgin olive-oil bioactive component. Food Funct. 2011, 2, 423-428. [CrossRef]

14. Segura Palacios, J.M.; Blazquez Sanchez, N.; Rivas Ruiz, F.; Aguilar Bernier, M.; Ramirez Lopez, B.; Sanchez, M.E.F.; de Troya Martin, M. Topical treatment with oleocanthal extract in reducing inflammatory reactions after photodynamic therapy: A prospective quasi-experimental pilot study. Complement. Ther. Med. 2019, 42, 298-301. [CrossRef]

15. Pang, K.L.; Chin, K.Y. The Biological Activities of Oleocanthal from a Molecular Perspective. Nutrients 2018, 10, 570. [CrossRef] 
16. Cusimano, A.; Balasus, D.; Azzolina, A.; Augello, G.; Emma, M.R.; Di Sano, C.; Gramignoli, R.; Strom, S.C.; McCubrey, J.A.; Montalto, G.; et al. Oleocanthal exerts antitumor effects on human liver and colon cancer cells through ROS generation. Int. J. Oncol. 2017, 51, 533-544. [CrossRef]

17. Cicerale, S.; Lucas, L.J.; Keast, R.S. Antimicrobial, antioxidant and anti-inflammatory phenolic activities in extra virgin olive oil. Curr. Opin. Biotechnol. 2012, 23, 129-135. [CrossRef]

18. Booth, J.N., 3rd; Colantonio, L.D.; Howard, G.; Safford, M.M.; Banach, M.; Reynolds, K.; Cushman, M.; Muntner, P. Healthy lifestyle factors and incident heart disease and mortality in candidates for primary prevention with statin therapy. Int. J. Cardiol. 2016, 207, 196-202. [CrossRef]

19. Khodarahmi, M.; Asghari-Jafarabadi, M.; Abbasalizad Farhangi, M. A structural equation modeling approach for the association of a healthy eating index with metabolic syndrome and cardio-metabolic risk factors among obese individuals. PLoS ONE 2019, 14, e0219193. [CrossRef]

20. Patti, A.M.; Al-Rasadi, K.; Giglio, R.V.; Nikolic, D.; Mannina, C.; Castellino, G.; Chianetta, R.; Banach, M.; Cicero, A.F.G.; Lippi, G.; et al. Natural approaches in metabolic syndrome management. Arch. Med. Sci. 2018, 14, 422-441. [CrossRef]

21. Perez-Martinez, P.; Mikhailidis, D.P.; Athyros, V.G.; Bullo, M.; Couture, P.; Covas, M.I.; de Koning, L.; Delgado-Lista, J.; Diaz-Lopez, A.; Drevon, C.A.; et al. Lifestyle recommendations for the prevention and management of metabolic syndrome: An international panel recommendation. Nutr. Rev. 2017, 75, 307-326. [CrossRef] [PubMed]

22. Toth, P.P.; Patti, A.M.; Nikolic, D.; Giglio, R.V.; Castellino, G.; Biancucci, T.; Geraci, F.; David, S.; Montalto, G.; Rizvi, A.; et al. Bergamot Reduces Plasma Lipids, Atherogenic Small Dense LDL, and Subclinical Atherosclerosis in Subjects with Moderate Hypercholesterolemia: A 6 Months Prospective Study. Front. Pharmacol. 2015, 6, 299. [CrossRef]

23. Fogacci, F.; Grassi, D.; Rizzo, M.; Cicero, A.F.G. Metabolic effect of berberine-silymarin association: A meta-analysis of randomized, double-blind, placebo-controlled clinical trials. Phytother. Res. 2019, 33, 862-870. [CrossRef] [PubMed]

24. Patti, A.M.; Al-Rasadi, K.; Katsiki, N.; Banerjee, Y.; Nikolic, D.; Vanella, L.; Giglio, R.V.; Giannone, V.A.; Montalto, G.; Rizzo, M. Effect of a Natural Supplement Containing Curcuma Longa, Guggul, and Chlorogenic Acid in Patients With Metabolic Syndrome. Angiology 2015, 66, 856-861. [CrossRef]

25. Cicero, A.F.G.; Fogacci, F.; Bove, M.; Veronesi, M.; Rizzo, M.; Giovannini, M.; Borghi, C. Short-Term Effects of a Combined Nutraceutical on Lipid Level, Fatty Liver Biomarkers, Hemodynamic Parameters, and Estimated Cardiovascular Disease Risk: A Double-Blind, Placebo-Controlled Randomized Clinical Trial. Adv. Ther. 2017, 34, 1966-1975. [CrossRef] [PubMed]

26. Sonmez, A.; Nikolic, D.; Dogru, T.; Ercin, C.N.; Genc, H.; Cesur, M.; Tapan, S.; Karslioglu, Y.; Montalto, G.; Banach, M.; et al. Low- and high-density lipoprotein subclasses in subjects with nonalcoholic fatty liver disease. J. Clin. Lipidol. 2015, 9, 576-582. [CrossRef]

27. Magan-Fernandez, A.; Rizzo, M.; Montalto, G.; Marchesini, G. Statins in liver disease: Not only prevention of cardiovascular events. Expert Rev. Gastroenterol. Hepatol. 2018, 12, 743-744. [CrossRef]

28. Rizvi, A.A.; Patti, A.M.; Giglio, R.V.; Nikolic, D.; Amato, A.; Al-Busaidi, N.; Al-Rasadi, K.; Soresi, M.; Banach, M.; Montalto, G.; et al. Liraglutide improves carotid intima-media thickness in patients with type 2 diabetes and non-alcoholic fatty liver disease: An 8-month prospective pilot study. Expert Opin. Biol. Ther. 2015, 15, 1391-1397. [CrossRef]

29. Targher, G.; Byrne, C.D.; Tilg, H. NAFLD and increased risk of cardiovascular disease: Clinical associations, pathophysiological mechanisms and pharmacological implications. Gut 2020, 69, 1691-1705. [CrossRef]

30. Castellino, G.; Nikolic, D.; Magan-Fernandez, A.; Malfa, G.A.; Chianetta, R.; Patti, A.M.; Amato, A.; Montalto, G.; Toth, P.P.; Banach, M.; et al. Altilix((R)) Supplement Containing Chlorogenic Acid and Luteolin Improved Hepatic and Cardiometabolic Parameters in Subjects with Metabolic Syndrome: A 6 Month Randomized, Double-Blind, Placebo-Controlled Study. Nutrients 2019, 11, 2580. [CrossRef]

31. Ginter, E.; Simko, V. Recent data on Mediterranean diet, cardiovascular disease, cancer, diabetes and life expectancy. Bratisl. Lek. Listy 2015, 116, 346-348. [CrossRef] [PubMed]

32. Tosti, V.; Bertozzi, B.; Fontana, L. Health Benefits of the Mediterranean Diet: Metabolic and Molecular Mechanisms. J. Gerontol. A Biol. Sci. Med. Sci. 2018, 73, 318-326. [CrossRef] [PubMed] 
33. Banach, M.; Patti, A.M.; Giglio, R.V.; Cicero, A.F.G.; Atanasov, A.G.; Bajraktari, G.; Bruckert, E.; Descamps, O.; Djuric, D.M.; Ezhov, M.; et al. The Role of Nutraceuticals in Statin Intolerant Patients. J. Am. Coll. Cardiol. 2018, 72, 96-118. [CrossRef] [PubMed]

34. Casas, R.; Estruch, R.; Sacanella, E. The Protective Effects of Extra Virgin Olive Oil on Immune-mediated Inflammatory Responses. Endocr. Metab. Immune Disord. Drug Targets 2018, 18, 23-35. [CrossRef]

35. Martinez-Gonzalez, M.A.; Salas-Salvado, J.; Estruch, R.; Corella, D.; Fito, M.; Ros, E.; Predimed, I. Benefits of the Mediterranean Diet: Insights From the PREDIMED Study. Prog. Cardiovasc. Dis. 2015, 58, 50-60. [CrossRef]

36. Mazzocchi, A.; Leone, L.; Agostoni, C.; Pali-Scholl, I. The Secrets of the Mediterranean Diet. Does [Only] Olive Oil Matter? Nutrients 2019, 11, 2941. [CrossRef]

37. Covas, M.I.; Konstantinidou, V.; Fito, M. Olive oil and cardiovascular health. J. Cardiovasc. Pharmacol. 2009, 54, 477-482. [CrossRef]

38. Masala, G.; Bendinelli, B.; Versari, D.; Saieva, C.; Ceroti, M.; Santagiuliana, F.; Caini, S.; Salvini, S.; Sera, F.; Taddei, S.; et al. Anthropometric and dietary determinants of blood pressure in over 7000 Mediterranean women: The European Prospective Investigation into Cancer and Nutrition-Florence cohort. J. Hypertens. 2008, 26, 2112-2120. [CrossRef]

39. Pedret, A.; Fernandez-Castillejo, S.; Valls, R.M.; Catalan, U.; Rubio, L.; Romeu, M.; Macia, A.; Lopez de Las Hazas, M.C.; Farras, M.; Giralt, M.; et al. Cardiovascular Benefits of Phenol-Enriched Virgin Olive Oils: New Insights from the Virgin Olive Oil and HDL Functionality (VOHF) Study. Mol. Nutr. Food Res. 2018, 62, e1800456. [CrossRef]

40. Luisi, M.L.E.; Lucarini, L.; Biffi, B.; Rafanelli, E.; Pietramellara, G.; Durante, M.; Vidali, S.; Provensi, G.; Madiai, S.; Gheri, C.F.; et al. Effect of Mediterranean Diet Enriched in High Quality Extra Virgin Olive Oil on Oxidative Stress, Inflammation and Gut Microbiota in Obese and Normal Weight Adult Subjects. Front. Pharmacol. 2019, 10, 1366. [CrossRef]

41. Violi, F.; Loffredo, L.; Pignatelli, P.; Angelico, F.; Bartimoccia, S.; Nocella, C.; Cangemi, R.; Petruccioli, A.; Monticolo, R.; Pastori, D.; et al. Extra virgin olive oil use is associated with improved post-prandial blood glucose and LDL cholesterol in healthy subjects. Nutr. Diabetes 2015, 5, e172. [CrossRef] [PubMed]

42. Patti, A.M.; Toth, P.P.; Giglio, R.V.; Banach, M.; Noto, M.; Nikolic, D.; Montalto, G.; Rizzo, M. Nutraceuticals as an Important Part of Combination Therapy in Dyslipidaemia. Curr. Pharm. Des. 2017, 23, 2496-2503. [CrossRef] [PubMed]

43. Schwingshackl, L.; Krause, M.; Schmucker, C.; Hoffmann, G.; Rucker, G.; Meerpohl, J.J. Impact of different types of olive oil on cardiovascular risk factors: A systematic review and network meta-analysis. Nutr. Metab. Cardiovasc. Dis. 2019, 29, 1030-1039. [CrossRef] [PubMed]

44. Galvao Candido, F.; Xavier Valente, F.; da Silva, L.E.; Goncalves Leao Coelho, O.; Gouveia Peluzio, M.D.C.; Goncalves Alfenas, R.C. Consumption of extra virgin olive oil improves body composition and blood pressure in women with excess body fat: A randomized, double-blinded, placebo-controlled clinical trial. Eur. J. Nutr. 2018, 57, 2445-2455. [CrossRef]

45. Sarapis, K.; Thomas, C.J.; Hoskin, J.; George, E.S.; Marx, W.; Mayr, H.L.; Kennedy, G.; Pipingas, A.; Willcox, J.C.; Prendergast, L.A.; et al. The Effect of High Polyphenol Extra Virgin Olive Oil on Blood Pressure and Arterial Stiffness in Healthy Australian Adults: A Randomized, Controlled, Cross-Over Study. Nutrients 2020, 12, 2272. [CrossRef]

46. Owen, R.W.; Giacosa, A.; Hull, W.E.; Haubner, R.; Wurtele, G.; Spiegelhalder, B.; Bartsch, H. Olive-oil consumption and health: The possible role of antioxidants. Lancet Oncol. 2000, 1, 107-112. [CrossRef]

47. Bendinelli, B.; Masala, G.; Saieva, C.; Salvini, S.; Calonico, C.; Sacerdote, C.; Agnoli, C.; Grioni, S.; Frasca, G.; Mattiello, A.; et al. Fruit, vegetables, and olive oil and risk of coronary heart disease in Italian women: The EPICOR Study. Am. J. Clin. Nutr. 2011, 93, 275-283. [CrossRef]

48. Carnevale, R.; Pignatelli, P.; Nocella, C.; Loffredo, L.; Pastori, D.; Vicario, T.; Petruccioli, A.; Bartimoccia, S.; Violi, F. Extra virgin olive oil blunt post-prandial oxidative stress via NOX2 down-regulation. Atherosclerosis 2014, 235, 649-658. [CrossRef]

49. Basterra-Gortari, F.J.; Ruiz-Canela, M.; Martinez-Gonzalez, M.A.; Babio, N.; Sorli, J.V.; Fito, M.; Ros, E.; Gomez-Gracia, E.; Fiol, M.; Lapetra, J.; et al. Effects of a Mediterranean Eating Plan on the Need for Glucose-Lowering Medications in Participants With Type 2 Diabetes: A Subgroup Analysis of the PREDIMED Trial. Diabetes Care 2019, 42, 1390-1397. [CrossRef] 
50. Villani, A.; Sultana, J.; Doecke, J.; Mantzioris, E. Differences in the interpretation of a modernized Mediterranean diet prescribed in intervention studies for the management of type 2 diabetes: How closely does this align with a traditional Mediterranean diet? Eur. J. Nutr. 2019, 58, 1369-1380. [CrossRef]

51. Estruch, R.; Ros, E.; Salas-Salvado, J.; Covas, M.I.; Corella, D.; Aros, F.; Gomez-Gracia, E.; Ruiz-Gutierrez, V.; Fiol, M.; Lapetra, J.; et al. Primary prevention of cardiovascular disease with a Mediterranean diet. N. Engl. J. Med. 2013, 368, 1279-1290. [CrossRef] [PubMed]

52. Rizzo, M.; Rizvi, A.A.; Rini, G.B.; Berneis, K. The therapeutic modulation of atherogenic dyslipidemia and inflammatory markers in the metabolic syndrome: What is the clinical relevance? Acta Diabetol. 2009, 46, 1-11. [CrossRef] [PubMed]

53. Corrado, E.; Rizzo, M.; Coppola, G.; Fattouch, K.; Novo, G.; Marturana, I.; Ferrara, F.; Novo, S. An update on the role of markers of inflammation in atherosclerosis. J. Atheroscler. Thromb. 2010, 17, 1-11. [CrossRef] [PubMed]

54. Corrado, E.; Rizzo, M.; Tantillo, R.; Muratori, I.; Bonura, F.; Vitale, G.; Novo, S. Markers of inflammation and infection influence the outcome of patients with baseline asymptomatic carotid lesions: A 5-year follow-up study. Stroke 2006, 37, 482-486. [CrossRef]

55. Abate, N.; Sallam, H.S.; Rizzo, M.; Nikolic, D.; Obradovic, M.; Bjelogrlic, P.; Isenovic, E.R. Resistin: An inflammatory cytokine. Role in cardiovascular diseases, diabetes and the metabolic syndrome. Curr. Pharm. Des. 2014, 20, 4961-4969. [CrossRef]

56. Kirichenko, T.V.; Sobenin, I.A.; Nikolic, D.; Rizzo, M.; Orekhov, A.N. Anti-cytokine therapy for prevention of atherosclerosis. Phytomedicine 2016, 23, 1198-1210. [CrossRef]

57. Haidara, M.; Mikhailidis, D.P.; Yassin, H.Z.; Dobutovic, B.; Smiljanic, K.T.; Soskic, S.; Mousa, S.A.; Rizzo, M.; Isenovic, E.R. Evaluation of the possible contribution of antioxidants administration in metabolic syndrome. Curr. Pharm. Des. 2011, 17, 3699-3712. [CrossRef]

58. Zhao, Y.; Evans, M.A.; Allison, M.A.; Bertoni, A.G.; Budoff, M.J.; Criqui, M.H.; Malik, S.; Ouyang, P.; Polak, J.F.; Wong, N.D. Multisite atherosclerosis in subjects with metabolic syndrome and diabetes and relation to cardiovascular events: The Multi-Ethnic Study of Atherosclerosis. Atherosclerosis 2019, 282, 202-209. [CrossRef]

59. Piers, L.S.; Walker, K.Z.; Stoney, R.M.; Soares, M.J.; O'Dea, K. The influence of the type of dietary fat on postprandial fat oxidation rates: Monounsaturated (olive oil) vs saturated fat (cream). Int. J. Obes. Relat. Metab. Disord. 2002, 26, 814-821. [CrossRef]

60. Alvarez-Perez, J.; Sanchez-Villegas, A.; Diaz-Benitez, E.M.; Ruano-Rodriguez, C.; Corella, D.; Martinez-Gonzalez, M.A.; Estruch, R.; Salas-Salvado, J.; Serra-Majem, L.; Investigators, P.S. Influence of a Mediterranean Dietary Pattern on Body Fat Distribution: Results of the PREDIMED-Canarias Intervention Randomized Trial. J. Am. Coll. Nutr. 2016, 35, 568-580. [CrossRef]

61. Rozati, M.; Barnett, J.; Wu, D.; Handelman, G.; Saltzman, E.; Wilson, T.; Li, L.; Wang, J.; Marcos, A.; Ordovas, J.M.; et al. Cardio-metabolic and immunological impacts of extra virgin olive oil consumption in overweight and obese older adults: A randomized controlled trial. Nutr. Metab. 2015, 12, 28. [CrossRef] [PubMed]

62. Covas, M.I.; Nyyssonen, K.; Poulsen, H.E.; Kaikkonen, J.; Zunft, H.J.; Kiesewetter, H.; Gaddi, A.; de la Torre, R.; Mursu, J.; Baumler, H.; et al. The effect of polyphenols in olive oil on heart disease risk factors: A randomized trial. Ann. Intern. Med. 2006, 145, 333-341. [CrossRef] [PubMed]

63. Cruz, M.A.; Cruz, J.F.; Macena, L.B.; de Santana, D.S.; Oliveira, C.C.; Lima, S.O.; Franca, A.V. Association of the Nonalcoholic Hepatic Steatosis and Its Degrees With the Values of Liver Enzymes and Homeostasis Model Assessment-Insulin Resistance Index. Gastroenterol. Res. 2015, 8, 260-264. [CrossRef] [PubMed]

64. Al-Seeni, M.N.; El Rabey, H.A.; Zamzami, M.A.; Alnefayee, A.M. The hepatoprotective activity of olive oil and Nigella sativa oil against $\mathrm{CCl} 4$ induced hepatotoxicity in male rats. BMC Complement. Altern. Med. 2016, 16, 438. [CrossRef] [PubMed]

65. Szychlinska, M.A.; Castrogiovanni, P.; Trovato, F.M.; Nsir, H.; Zarrouk, M.; Lo Furno, D.; Di Rosa, M.; Imbesi, R.; Musumeci, G. Physical activity and Mediterranean diet based on olive tree phenolic compounds from two different geographical areas have protective effects on early osteoarthritis, muscle atrophy and hepatic steatosis. Eur. J. Nutr. 2019, 58, 565-581. [CrossRef] [PubMed] 
66. Pinto, X.; Fanlo-Maresma, M.; Corbella, E.; Corbella, X.; Mitjavila, M.T.; Moreno, J.J.; Casas, R.; Estruch, R.; Corella, D.; Bullo, M.; et al. A Mediterranean Diet Rich in Extra-Virgin Olive Oil Is Associated with a Reduced Prevalence of Nonalcoholic Fatty Liver Disease in Older Individuals at High Cardiovascular Risk. J. Nutr. 2019, 149, 1920-1929. [CrossRef] [PubMed]

67. Bays, H.E. Adiposopathy is "sick fat" a cardiovascular disease? J. Am. Coll. Cardiol. 2011, 57, $2461-2473$. [CrossRef] [PubMed]

68. Despres, J.P. Body fat distribution and risk of cardiovascular disease: An update. Circulation 2012, 126, 1301-1313. [CrossRef]

69. Goedecke, J.H.; Utzschneider, K.; Faulenbach, M.V.; Rizzo, M.; Berneis, K.; Spinas, G.A.; Dave, J.A.; Levitt, N.S.; Lambert, E.V.; Olsson, T.; et al. Ethnic differences in serum lipoproteins and their determinants in South African women. Metabolism 2010, 59, 1341-1350. [CrossRef]

70. Berneis, K.; Rizzo, M.; Evans, J.; Rini, G.B.; Spinas, G.A.; Goedecke, J.H. Interleukin-18 levels are associated with low-density lipoproteins size. Eur. J. Clin. Investig. 2010, 40, 54-55. [CrossRef]

71. Rizzo, M.; Berneis, K. Who needs to care about small, dense low-density lipoproteins? Int. J. Clin. Pract. 2007, 61, 1949-1956. [CrossRef] [PubMed]

72. Rizzo, M.; Berneis, K.; Zeljkovic, A.; Vekic, J. Should we routinely measure low-density and high-density lipoprotein subclasses? Clin. Lab. 2009, 55, 421-429. [PubMed]

73. Rizzo, M.; Kotur-Stevuljevic, J.; Berneis, K.; Spinas, G.; Rini, G.B.; Jelic-Ivanovic, Z.; SpasojevicKalimanovska, V.; Vekic, J. Atherogenic dyslipidemia and oxidative stress: A new look. Transl. Res. 2009, 153, 217-223. [CrossRef] [PubMed]

74. Rizzo, M.; Berneis, K. Small, dense low-density-lipoproteins and the metabolic syndrome. Diabetes Metab. Res. Rev. 2007, 23, 14-20. [CrossRef] [PubMed]

75. Rizzo, M.; Pernice, V.; Frasheri, A.; Di Lorenzo, G.; Rini, G.B.; Spinas, G.A.; Berneis, K. Small, dense low-density lipoproteins (LDL) are predictors of cardio- and cerebro-vascular events in subjects with the metabolic syndrome. Clin. Endocrinol. 2009, 70, 870-875. [CrossRef] [PubMed]

76. Barylski, M.; Toth, P.P.; Nikolic, D.; Banach, M.; Rizzo, M.; Montalto, G. Emerging therapies for raising high-density lipoprotein cholesterol (HDL-C) and augmenting HDL particle functionality. Best Pract. Res. Clin. Endocrinol. Metab. 2014, 28, 453-461. [CrossRef]

77. Kinger, M.; Kumar, S.; Kumar, V. Some Important Dietary Polyphenolic Compounds: An Anti-inflammatory and Immunoregulatory Perspective. Mini Rev. Med. Chem. 2018, 18, 1270-1282. [CrossRef]

78. Parkinson, L.; Keast, R. Oleocanthal, a phenolic derived from virgin olive oil: A review of the beneficial effects on inflammatory disease. Int. J. Mol. Sci. 2014, 15, 12323-12334. [CrossRef]

79. Carpi, S.; Scoditti, E.; Massaro, M.; Polini, B.; Manera, C.; Digiacomo, M.; Esposito Salsano, J.; Poli, G.; Tuccinardi, T.; Doccini, S.; et al. The Extra-Virgin Olive Oil Polyphenols Oleocanthal and Oleacein Counteract Inflammation-Related Gene and miRNA Expression in Adipocytes by Attenuating NF-kappaB Activation. Nutrients 2019, 11, 2855. [CrossRef]

80. Garcia-Bonilla, L.; Benakis, C.; Moore, J.; Iadecola, C.; Anrather, J. Immune mechanisms in cerebral ischemic tolerance. Front. Neurosci. 2014, 8, 44. [CrossRef]

81. Alberti, K.G.; Eckel, R.H.; Grundy, S.M.; Zimmet, P.Z.; Cleeman, J.I.; Donato, K.A.; Fruchart, J.C.; James, W.P.; Loria, C.M.; Smith, S.C., Jr.; et al. Harmonizing the metabolic syndrome: A joint interim statement of the International Diabetes Federation Task Force on Epidemiology and Prevention; National Heart, Lung, and Blood Institute; American Heart Association; World Heart Federation; International Atherosclerosis Society; and International Association for the Study of Obesity. Circulation 2009, 120, 1640-1645. [CrossRef] [PubMed]

82. Riboli, E.; Kaaks, R. The EPIC Project: Rationale and study design. European Prospective Investigation into Cancer and Nutrition. Int. J. Epidemiol. 1997, 26 (Suppl. 1), S6-S14. [CrossRef]

83. Victor, R.G.; Lynch, K.; Li, N.; Blyler, C.; Muhammad, E.; Handler, J.; Brettler, J.; Rashid, M.; Hsu, B.; Foxx-Drew, D.; et al. A Cluster-Randomized Trial of Blood-Pressure Reduction in Black Barbershops. N. Engl. J. Med. 2018, 378, 1291-1301. [CrossRef] [PubMed]

84. Bedogni, G.; Bellentani, S.; Miglioli, L.; Masutti, F.; Passalacqua, M.; Castiglione, A.; Tiribelli, C. The Fatty Liver Index: A simple and accurate predictor of hepatic steatosis in the general population. BMC Gastroenterol. 2006, 6, 33. [CrossRef] [PubMed]

85. Dinarello, C.A. The IL-1 family and inflammatory diseases. Clin. Exp. Rheumatol. 2002, 20, S1-S13. [PubMed] 
86. Kolls, J.K.; Linden, A. Interleukin-17 family members and inflammation. Immunity 2004, 21, 467-476. [CrossRef] [PubMed]

87. Popa, C.; Netea, M.G.; van Riel, P.L.; van der Meer, J.W.; Stalenhoef, A.F. The role of TNF-alpha in chronic inflammatory conditions, intermediary metabolism, and cardiovascular risk. J. Lipid Res. 2007, 48, 751-762. [CrossRef]

88. Scheller, J.; Chalaris, A.; Schmidt-Arras, D.; Rose-John, S. The pro- and anti-inflammatory properties of the cytokine interleukin-6. Biochim. Biophys. Acta 2011, 1813, 878-888. [CrossRef]

89. Mosser, D.M.; Zhang, X. Interleukin-10: New perspectives on an old cytokine. Immunol. Rev. 2008, 226, 205-218. [CrossRef]

90. Bio-Plex ${ }^{\mathrm{TM} C y t o k i n e ~ A s s a y . ~ A v a i l a b l e ~ o n l i n e: ~ h t t p: / / w w w . f i l g e n . j p / P r o d u c t / B i o s c i e n c e 19-B i o p l e x / B i o-P l e x \% ~}$ 20Cytokine\%20Assay\%20Manual.pdf (accessed on 19 August 2020).

91. Saverymuttu, S.H.; Joseph, A.E.; Maxwell, J.D. Ultrasound scanning in the detection of hepatic fibrosis and steatosis. Br. Med. J. (Clin. Res. Ed) 1986, 292, 13-15. [CrossRef]

92. Soresi, M.; Giannitrapani, L.; Florena, A.M.; La Spada, E.; Di Gesaro, V.; Rappa, F.; Alessandri, A.; Tripi, S.; Romano, M.; Montalto, G. Reliability of the bright liver echo pattern in diagnosing steatosis in patients with cryptogenic and HCV-related hypertransaminasaemia. Clin. Radiol. 2009, 64, 1181-1187. [CrossRef] [PubMed]

93. Armellini, F.; Zamboni, M.; Rigo, L.; Todesco, T.; Bergamo-Andreis, I.A.; Procacci, C.; Bosello, O. The contribution of sonography to the measurement of intra-abdominal fat. J. Clin. Ultrasound 1990, 18, 563-567. [CrossRef] [PubMed]

94. Suzuki, R.; Watanabe, S.; Hirai, Y.; Akiyama, K.; Nishide, T.; Matsushima, Y.; Murayama, H.; Ohshima, H.; Shinomiya, M.; Shirai, K.; et al. Abdominal wall fat index, estimated by ultrasonography, for assessment of the ratio of visceral fat to subcutaneous fat in the abdomen. Am. J. Med. 1993, 95, 309-314. [CrossRef]

(C) 2020 by the authors. Licensee MDPI, Basel, Switzerland. This article is an open access article distributed under the terms and conditions of the Creative Commons Attribution (CC BY) license (http://creativecommons.org/licenses/by/4.0/). 